\title{
Editorial
}

\section{The Elderly are Facing HIV/AIDS Crisis}

\author{
Chunguang Fu, BSc; Chengjun Sun, PhD* \\ School of Management and Economics, Kunming University of Science and Technology, 253, Xuefu Road, Kunming, Yunnan 650093, China
}

"Corresponding author

Chengjun Sun, PhD

Assistant Professor, School of Management and Economics, Kunming University of Science and Technology, 253 Xuefu Road, Kunming, Yunnan 650093, China

E-mail: cjunsun@gmail.com

\section{Article information}

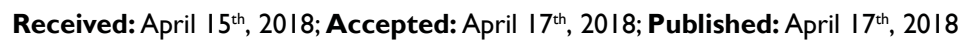

\section{Cite this article}

Fu C, Sun C. The elderly are facing HIV/AIDS crisis. HIVIAIDS Res Treat Open J. 20I8; 5(I): el-e2. doi: 10.17I40/HARTOJ-5-e0I I

\begin{abstract}
7 he world's population is aging, and the population aged 60 or over is growing faster than all younger age groups globally. In 2017, there are an estimated 962 million people aged 60 or over in the world, comprising $13 \%$ of the global population, and growing at a rate of around 3\% per year. Currently, Europe has the greatest percentage $(25 \%)$ of the population aged 60 or over. The elderly population (aged 60 or over) worldwide is expected to be 1.4 billion in 2030 , most of whom $(80 \%)$ would be living in developing countries. $^{1}$
\end{abstract}

Meanwhile, the number of HIV-infected elderly is increasing globally. ${ }^{2}$ It was estimated that the percentage of people living with HIV aged 50 or over had increased more than $17 \%$ over the past decade. ${ }^{3}$ In 2016, the number of reported human immunodeficiency virus/acquired immunodeficiency syndrome (HIV/ AIDS) cases among males age 60 or over in China more than tripled from that reported in $2010 .{ }^{4}$ HIV diagnosis is increasing in older adults in Western and Central Europe and North America, Eastern Europe and Central Asia, Latin America, Caribbean, Sub-Saharan Africa, Asia and the Pacific, and the Middle East and North Africa. ${ }^{5}$ In HIV-infected elderly, higher morbidity and mortality, rapid progression to AIDS, and shorter survival period have been confirmed by many scientists ${ }^{6-9}$ : they have become more vulnerable.

Data collected from the elderly suggests a belief that HIV is an infection acquired only by younger people. The lure of easy sex with prostitutes/sex workers and the lack of safe sex knowledge may expose an increasing number of the elderly to the danger of HIV/AIDS. Older people diagnosed with HIV tend to face harsh moral judgments and social discrimination than their younger counterparts, which discourage them from seeking medical counseling and testing. Moreover, lack access to counseling and testing gets the elderly away from treatment. In most less developed countries, the priority in health care services is not given to the elderly living with HIV.
Although, the global attention has been paid to the epidemic of HIV/AIDS, HIV infection among the elderly is a neglected area of study. ${ }^{10}$ The resulting diseases may burden the public health, and however, the ignorance of it addresses a significant blind spot in the response to the epidemic of HIV/AIDS. The governments and non-governmental bodies need to adopt tailored prevention and mitigation policies that address the needs of elderly people. It's time for us to act now, with no delays, to launch HIV/ AIDS awareness and prevention campaigns, and to initiate statesponsored HIV/AIDS treatment programs, targeting the elderly.

\section{ACKNOWLEDGEMENT}

The authors acknowledge financial support from the project of KMUST for Fostering Talents in provincial level (KKSY201608050) and the project of Yunnan Education Department (2016ZZX055). The author would like to acknowledgement Kunming University of Science and Technology research facility and support.

\section{COMPETING FINANCIAL INTERESTS}

The authors declare no competing financial interests.

\section{REFERENCES}

1. United Nations. Global Issues: Ageing. Web site. http://www. un.org/en/sections/issues-depth/ageing/. Accessed April 14, 2018.

2. Mahy M, Autenrieth CS, Stanecki K, Wynd S. Increasing trends in HIV prevalence among people aged 50 years and older: Evidence from estimates and survey data. AIDS. 2014; 28(Suppl 4): S453-S459. doi: 10.1097/QAD.0000000000000479

3. Centers for Disease Control and Prevention. HIV/AIDS Sur- 
veillance Report. CDC, Atlanta, Ga, USA, 2006. Web site. http:// www.cdc.gov/hiv/topics/surveillance/resources/reports. Accessed April 14, 2018.

4. Zhang J. HIV cases rise steadily over decade. China Daily. 2017. Web site. http://english.cctv.com/2017/11/14/ARTI96ReIhz6MkYI5waZohgZ171114.shtml. Accessed April 14, 2018.

5. UNAIDS. HIV and aging: A special supplement to the UNAIDS report on the global AIDS epidemic 2013. Web site. http://www. unaids.org/sites/default/files/media_asset/20131101_JC2563_ hiv-and-aging_en_0.pdf. Accessed April 14, 2018.

6. Balslev U, Monforte AD, Stergiou G, et al. Influence of age on rates of new AIDS-defining diseases and survival in 6546 AIDS patients. Scand J Infect Dis. 1997; 29(4): 337-343. doi: 10.3109/00365549709011827
7. Grabar S, Kousignian I, Sobel A, et al. Immunologic and clinical responses to highly active antiretroviral therapy over 50 years of age. Results from the French Hospital Database on HIV. AIDS. 2004; 18: 2029-2038.

8. Nogueras M, Navarro G, Anton E. Epidemiological and clinical features, response to HAART, and survival in HIV-infected patients diagnosed at the age of 50 or more. BMC Infect Dis. 2006; 6: 159. doi: 10.1186/1471-2334-6-159

9. Butt AA, Dascomb KK, Desalvo KB, Bazzano L, Kissinger PJ, Szerlip HM. Human immunodeficiency virus infection in elderly patients. South Med J. 2001; 94: 397-400.

10. Yang W, Shu Z, Lam J, Sun C. Global dynamics of an HIV model incorporating senior male clients. Applied Mathematics and Computation. 2017; 311: 203-216. doi: 10.1016/j.amc.2017.05.030 